This article is a post-review, pre-publication version of a book chapter. For citation purposes, please see the original: Craig, T.S. (2017). Enabling capabilities in an Engineering extended curriculum programme. In R. Kapp \& B. Bangeni (Eds.) Negotiating Learning and Identity in Higher Education. Bloomsbury Press.

\title{
Enabling Capabilities in an Engineering Extended Curriculum Programme
}

\author{
Tracy S. Craig
}

\section{Introduction}

The Academic Support Programme for Engineering (ASPECT) was founded in 1988 to increase access to engineering studies at the University of Cape Town (UCT) for students from disadvantaged backgrounds and to provide academic support for those students (Sass 1988; Meyer and Sass 1992; Jawitz 1994; Jawitz and Scott 1997). The legacy of apartheid is such that graduation rates of students from disadvantaged backgrounds are still low. The need for the Programme to provide academic (and other) support to students from a previously disadvantaged educational system has been recognized as an important part of the University's agenda of access and transformation, providing educational opportunities and resources to ameliorate inequalities in our society. The students who enter the Programme at the beginning of their first year at UCT are South African black students. ASPECT students (in general, not exclusively) enter under special admissions circumstances. In general, the students have been successful, despite coming from poorly-resourced home backgrounds and schools with a weak academic record. They are frequently the first member of their family, school or larger community to be accepted at university (Pym and Kapp 2013; Craig 2013; Kapp et al. 2014;).

The aim of ASPECT is to provide the necessary academic foundations which the students did not receive at school and to support students through the school-university transition, which is especially tough for first-generation, rural students with inadequate preparation from school (Pearce et al. 2015). Walker (2003: 171) points out that ' $\ldots$ in a class-stratified society widening participation is a matter of justice' and Nussbaum (2006: 387) agrees when she states that '... nothing could be more crucial to democracy than the education of its citizens'. The Programme's role is to provide marginalized students with crucial access to studies which can have a transformative effect on the individual, their family and on their greater communities.

The ASPECT model offers a decreased course load and additional support, with a particular focus on mathematics and physics. The students do the same courses as the mainstream students, at the same pace, but fewer of them at a time, resulting in spreading the four-year degree over five years. The model is one of 'more time, more tuition' (Kloot, Case and Marshal 2008: 803). Students in the ASPECT programme have a different experience to those in the mainstream programme in a number of ways: the ASPECT first-year class is smaller than the mainstream classes, roughly eighty in ASPECT to 500 in the mainstream, which allows the students and lecturers to get to know one another better and allows for varied class activities involving more interaction, active learning and group work. I am one of the mathematics lecturers on the Programme and while the primary focus of ASPECT is on supporting students' academic transitions, we recognize that the transition requires psychosocial support as well. For example, the ASPECT administrative assistant is far more than a 
secretary, filling a maternal role for students far from home and usually the first to hear of family, financial or other stressors.

In this chapter I use the lens of Amartya Sen's capability approach (see below) to identify the capabilities the Programme expects to enable, and compare them to the capabilities articulated by fifteen ASPECT students who participated in the longitudinal study. I examine the agreements and silences and observe that while certain key capabilities are being enabled as hoped, others are not well aligned across the Programme expectation/student experience divide. The success of ASPECT, as one small part of a much larger national programme of transformation and social justice in higher education, hinges in part on the successful enabling of capabilities which provide students with the potential to choose a life of value. I argue that the efficacy of ASPECT would be increased by a two-pronged approach, that of extending academic support further than first year as well as redesigning ASPECT as a welldefined learning community. This approach might address some of the perceived shortfalls while benefiting from existing strengths.

\section{The capability approach}

The capability approach is generally associated with Amartya Sen, a Nobel Prize-winning economist and philosopher. Sen developed the capability approach as a way of thinking about and evaluating human well-being and matters of social justice. Sen defines capability as 'a person's ability to do valuable acts or reach valuable states of being; [it] represents the alternative combinations of things a person is able to do or be' (Sen 1993: 30, my italics). In Sen's theoretical framework, achieved outcomes are termed functionings, while capabilities are the potential to achieve these functionings. Capabilities are opportunities to achieve while functionings are the actual achievement (Walker 2006; Walker and Unterhalter 2007).

Walker and Unterhalter (2007:8) suggest that 'the [capabilities] approach leads us to ask questions such as ... Do some people get more opportunities to convert their resources into capabilities than others?' In the South African context, as in many other places in the world, disparity of opportunity is undoubtedly the case. Despite countrywide access to basic education, the quality of that education can be extremely poor (Walker 2006; Christie 2010). Not only do social and political circumstances lead to unequal opportunities, but 'schooling can and in some cases does contribute to capability deprivation, often through reproducing existing inequalities' (Tikly and Barrett 2011:7). Students who gain entry into ASPECT are recognized as having the internal resources which could be converted into capabilities. The Programme aims to provide an environment where the students leave with well-developed capabilities and after that it is up to them to choose to realize their capabilities as functionings as much as educational and societal structures will allow.

\section{Methodology}

Following Walker (2006) I draw on Robeyns' (2003: 70-71) five criteria for listing capabilities: 
1. 'The list should be explicit, discussed, and defended.'

2. We should clarify the method used to generate the list.

3. The level of abstraction of the list should be appropriate for our objectives with respect to our use of the capability approach.

4. Policy makers should first draw up an ideal list, then a pragmatic list.

5. The list should include all important elements with no element reducible to another element.

Since it is not my purpose in this chapter to develop or critique policy, Robeyns' fourth criterion is not applicable here. I draw up and discuss an explicit list, however I do not defend it as an ideal list, nor can I be sure that the same list would have arisen through an analysis of a different data set.

The method used to generate the list of capabilities discussed in this chapter was produced by first recognizing and acknowledging the definition referenced earlier of a capability as an ability 'to do valuable acts' or an ability 'to reach valuable states of being' (Sen 1993: 30). Thereafter the annual interview transcripts of the engineering students participating in this study (up to five interviews per student) were examined for references made to 'acts' or 'being' enabled or constrained by the Programme. Parallel to engaging with the interview data, the available formal Programme documentation (a 2008 brochure sent out to prospective students and the 2009 Programme Review document, internal to the institution) was examined for references made to 'acts' or 'being' enabled or constrained by the Programme. Each of these data sources revealed expressions of capabilities as defined above, with areas of overlap as well as elements arising primarily from one source only.

When references to capabilities in the Programme documentation as well as in the data in the student interviews are extracted, the following 'abilities to be' or 'to reach valuable states of being' begin our list:

1. to be a university student;

2. to be a member of a valued community.

The abilities 'to do valuable acts' that can be recognized expand the list to include:

3. to transition to university studies;

4. to learn work habits and study skills;

5. to transition into second year and beyond;

6. to graduate in five years.

The capabilities listed here are expressed in general terms, clustering similar elements together, in order to adhere to Robeyns' fifth criterion, that the 'list should include all important elements with no element reducible to another element'. The list is sufficiently abstract for our purposes and includes all important elements recognized by the described method. Having drawn up this explicit list, the capabilities can be discussed, comparing and contrasting the voices of the students with that of the formal Programme documentation. 
This chapter draws on interview data from fifteen engineering students who participated in the longitudinal project and who joined the ASPECT extended degree programme as first years in 2009. The longitudinal approach with annual interviews provides successive 'snapshots' of the student's lives (Thomson 2009: 14), allowing one to gain insight (in this case) into the participants' subjective experience of having been part of the extended degree programme. Interview questions covered pre-university experiences, experiences of ASPECT across the years, academic progress and managing challenges, finances, experiences of mathematics and language, social life and hobbies, personal highlights and low points and future aspirations. Data was collected from multiple interviews for the majority of the fifteen ASPECT students who participated in the longitudinal projectt. Of the participants, nine have graduated, one is still completing the degree, four were academically excluded and one left the university before completion. In the student quotes used in this chapter the attributions are (Pseudonym, interview year) where the year is a number between 1 (2009) and 5 (2013).

\title{
Access: Embarking as a university student
}

ASPECT gives the students in the Programme the capability to be university students, the first capability on our list. The access role of ASPECT is crucial, because certain schoolleaving learners have the resources which can be converted into capabilities during their year in the Programme, allowing them to choose a life of value, that is, to become an engineer. The Programme Review document foregrounds the access purpose of the Programme, access which in many cases would not have been possible without the existence of the Programme:

\begin{abstract}
The primary role of ASPECT has thus been to provide access and academic support for black and coloured students that enter into the Engineering and Built Environment [EBE] faculty from poor schooling backgrounds and to give them the best preparation for the further years of engineering studies (ASPECT Review 2009: 4); and

The 'access' mission of the programme remains valid and there are still sufficient students who do graduate who would not have been admitted if it were not for the existence of ASPECT. (ASPECT Review 2009: 22)
\end{abstract}

Every year some of the students in the class begin their degree in the mainstream class and shift across to the ASPECT class. Those students had already gained access to the University, but were struggling with the mainstream demands and were concerned about their chances of completing the year. 'In Nussbaum's conceptualization, this student has the internal capabilities to handle academic work, but the (external) conditions in the institution to enhance her capabilities are missing or constrained.' (Walker and Unterhalter 2007:11). By choosing the extended degree programme, these students gain, through their own agency, where agency can be defined as 'the space where the individual acts with intentionality' (Case 2013: 31), the opportunity to enhance their capabilities and increase their chances of success. Walker (2005:105) points out that 'notions of agency are central to the capability 
approach. At the boundary of functionings and capabilities is the matter of choice, where a person exercises his or her agency, having the requisite set of capabilities.' Tsego is one of the students who made such a shift. Her metaphoric comment on the support offered by the Programme illustrates her conception of ASPECT as a site that would provide support that would facilitate her agency:

'ASPECT not only gave me a life vest, they made me swim as well because if you are in mainstream and you see that you are drowning, no one is there to say like - come out, like swim - or something like that but ASPECT did that, they were like - here is a life vest-swim' (Tsego, interview 4).

The capability of being a university student, in particular to be an engineering student, gained by access through ASPECT is a crucial point in the student's academic journey. Once physically present on UCT campus, with access to lecturers and tutors, the library, electronic resources and fellow students, the student is now in an advantageous position to convert personal and internal resources into capabilities and thereafter academic functionings. The student has the 'capability to aspire' (Walker 2006:17). Walker (2005:109) recognizes that 'The issue for those of us working in education is that schools, colleges and universities contribute, for many people quite substantially, to the formation of their capabilities to function.' Once enrolled in the ASPECT programme, it is the task of the ASPECT staff to support the students in converting their resources into the capabilities required of them, of allowing the students to achieve the potential recognized in them by acceptance into the Programme.

\section{Beyond embarkation: Transitioning to university studies}

The capabilities the ASPECT programme hopes to develop in the early stages of first-year studies (as expressed in the brochure and review) are to transition to university studies (3 on our list) and to learn work and study skills (4). Developing the capability to transition to university studies is understood to be supported by a variety of processes including, but not limited to, explicitly teaching topics superficially covered in the school syllabus (an example in mathematics would be log laws), explicitly focusing on problem solving in mathematics and physics, and paying attention to students' financial and accommodation needs. Developing the capability to learn work and study skills is addressed by the staff in the ASPECT programme in an ongoing manner both within and outside class. Within mathematics and physics classes, the teaching staff endeavour to instil good study skills specific to those disciplines. Outside those classes, the students are taught generic skills such as time management and technical report writing.

The aims of the Programme and the students appear to agree on the efforts to aid transition to university studies. The review document says:

'ASPECT strives to provide a supportive environment that is sensitive to students' academic, social and emotional needs in an attempt to address the 
This article is a post-review, pre-publication version of a book chapter. For citation purposes, please see the original: Craig, T.S. (2017). Enabling capabilities in an Engineering extended curriculum programme. In R. Kapp \& B. Bangeni (Eds.) Negotiating Learning and Identity in Higher Education. Bloomsbury Press.

difficult transition from school to prepare them for tertiary education' (ASPECT Review 2009: 4).

Most students do manage to transform their capability to transition into the achieved outcome of managing the first-year load. In their senior years, the students commented positively on ASPECT's role in closing the gap between school and university by providing individual support in their first year:

You know that is one of the difficult years for people because they have to adapt to everything but I found it quite differently because through the programme, ASPECT, you had all the support that you needed academicwise, even though I was not that social person but academic-wise but you had everything that you needed, [staff member], all the other ASPECT staff helping you through everything else (Chris, interview 4); and

I think it was, ASPECT helped me a lot, ... but because in ASPECT they do things differently compared to mainstream, I mean it helped me to change my strategy before it was too late ... being in ASPECT helped me to close that gap between high school and university. (Senzo, interview 5)

A particular point which students foregrounded (without being asked) was recognition of the value of the decreased load model. Coping with the demands of university studies is made possible by the decreased load, which allows more time per subject as well as time to develop a more rounded lifestyle, with interests outside academic studies:

Well first of all I would say [to incoming students] join ASPECT because obviously the academic load will be reduced significantly so that will give them enough time to adjust to the whole conditions at the university to be able to, for the next year you can progress' (Chris, interview 3); and Ifelt relieved [upon joining ASPECT], because now I had more time to like do other things instead of just study, like I get time to go to the gym, I get time to get extra lessons for things like piano, I play the piano...' (Tsego, interview 1)

A mismatch between the expectations of the Programme and the experience of the students is apparent in relation to the communication course. The course recognizes the centrality of language to learning in engineering and the struggles that students for whom English is an additional language are likely to have:

The communication course is primarily concerned with written and oral communication in a professional and technical setting (ASPECT Review 2009: 8); and

The [communication] course aims to develop first-year students' academic literacy in the context of the engineering curriculum and profession. Thus it focuses on nurturing sound academic writing and reading skills, as well as an awareness of and competency in a range of genres in engineering, 
This article is a post-review, pre-publication version of a book chapter. For citation purposes, please see the original: Craig, T.S. (2017). Enabling capabilities in an Engineering extended curriculum programme. In R. Kapp \& B. Bangeni (Eds.) Negotiating Learning and Identity in Higher Education. Bloomsbury Press.

including the academic essay, needs analysis, investigative report, poster and oral presentation. (ASPECT Review 2009: 22)

However, while the value of the communication course was often not recognized by the students at the time, some of the students continued to draw on the support of the lecturer in the years that followed, returning to ask for help with written course assignments, bursary applications and letters of various kinds. In five years, only one mention was made of the communication course, by a student asked, 'Would you say you have changed your approach to your writing compared to first year?':

'We did a course in first year which taught us a lot of the basics and setting out reports and all of that and from there I have used the same' (Leonard, interview 3).

The communication course is foregrounded in the Programme documentation for good reason: engineers need to be able to write and present technical reports. The course carries fewer credits than the concurrent mathematics and physics courses, perhaps suggesting (erroneously) to the students that the course is not to be valued. It is also possible that students avoided mentioning (or thinking about) the communication course due to the very language difficulties which the course was designed to address.

\section{The people: Being part of a valued community}

The Programme documentation acknowledges the community aspect of the Programme, but does not discuss it as a major feature. Rather, the strengths of the Programme are considered to be primarily academic and references to community, though present, are muted:

'Many students find the ASPECT office a home away from home and are there frequently just to talk with [administrative staff member]' (ASPECT Review 2009:8); and:

'Students soon feel at home in the ASPECT community ...' (ASPECT Brochure 2008: 1)

This contrasts with the students' responses, where a sense of community was strongly foregrounded and that sense of community persisted beyond first year. Academic advantages were certainly recognized by the students, but came across as secondary to the sense of community, which is 2 on our capabilities list. Apparent in the interview data is the value the students placed on the support they found by being part of the ASPECT community.

The participants emphasized the community aspect of the Programme repeatedly, up to interviews in year five. The community (staff as well as students) formed in their first year was valued by the students for a variety of reasons: first for the new friends made, second for being assured of continued curriculum support after first year, third for feeling that they are in a privileged position over mainstream students, fourth for valuing the diversity of the class and finally for having the opportunity to 'give back' as a mentor in later years. On the first point, in her second year Tsego described the communal aspect of ASPECT as the highlight of her first year: 
This article is a post-review, pre-publication version of a book chapter. For citation purposes, please see the original: Craig, T.S. (2017). Enabling capabilities in an Engineering extended curriculum programme. In R. Kapp \& B. Bangeni (Eds.) Negotiating Learning and Identity in Higher Education. Bloomsbury Press.

I have made a lot of good friends because in my ASPECT class it was this almost small group whereby we got to actually know each other more because we spent more time together and did a lot of things together like we did go out, to the beach maybe or maybe to have something to eat or something like that and ja, it worked out pretty well and we developed a study, we studied a lot of things together and that helped as well. (Tsego, interview 2)

The participants generally included staff members in their description of ASPECT as a 'family':

'It was like we had this whole family thing going on, you know we had a small class and ja [Afrikaans for 'yes'], it was, you could relate to the lecturers, you could pop by their office, they were always smiling and friendly, that type of thing' (Rethabile, interview 4).

Secondly, as members of the community, students can rely on continued support from the staff, lecturers as well as administrative staff, beyond their first-year direct involvement, as the two extracts below demonstrate:

I mean working very hard is one of those but again there is one lecturer that I also go and see in ASPECT, that is also keep motivating me to work hard because sometimes mathematics is hard and then you can drop your head a bit, but she is always saying you have to work hard and stay focused (Chris, interview 2); and

Like [administrative staff member], she is so helpful, like even this year I can go to her and ask her anything and when I had problems with registration, this semester, last semester, I would always just go to her, even though I went to the Civil Department, they didn't always know what was going on whereas I would go to [administrative staff member] and she would do everything for me. (Fatima, interview 2)

The students experienced a shift in perception during that first year, resulting in the third reason to value being in ASPECT. To begin with the students often felt uncomfortable being placed in the extended degree programme, all of them having been top achievers in their secondary schools. Towards the end of the first quarter of the academic year, students transfer across from the mainstream programme and the perception changes to being part of an exclusive and desirable community:

I was asking myself what is wrong with this ASPECT and then they gave us a mentor from ASPECT as well and then he told us 'No, don't worry about much, the class will be full, people from mainstream will come to us' ... And then actually what he was saying was true because there are some people who got rejected because the class was full, who want to go, who were willing to go ... to ASPECT, and then they end up doing, like, a decant 
This article is a post-review, pre-publication version of a book chapter. For citation purposes, please see the original: Craig, T.S. (2017). Enabling capabilities in an Engineering extended curriculum programme. In R. Kapp \& B. Bangeni (Eds.) Negotiating Learning and Identity in Higher Education. Bloomsbury Press.

course and when you are doing a decant course you are already in a fiveyear programme because there are courses that you can't do when you did not finish maths and physics (Senzo, interview 2);

The lecturers are much better, you kind of like, they set you up, you know, it helps a lot actually, and I think a lot of mainstream people also realise that. (Lesego, interview 1)

Fourth, the community was valued for being diverse:

'Ja, because I was in ASPECT, I think I met a lot of people from all over the place, so I have been exposed to different religious backgrounds, different people from different ... social classes' (Fatima, interview 2); and, 'In ASPECT there are different, you have different cultures, I am Xhosa, there are also Pedi guys, Sotho guys, Tswana guys, Venda and also a Chinese guy, ja so I can say sometimes we try to learn each other's languages, so it's fun staying here' (John, interview 1).

Finally, in their senior years, the students also valued being able to give back to the community by becoming mentors for the students following in their footsteps: It's going well because I'm also telling those students, I'm also giving them advice of how to maybe cope with their courses like explaining to them because some people may think ASPECT is for students maybe who are not serious about education, things like that, their education is at a low standard than others but ASPECT is a good thing, maybe some people think maths that is done in ASPECT is different from the maths that is done on the mainstream, as well as the physics, actually I do tell them that it's the same. (John, interview 2)

The capabilities enabled and developed by being an ASPECT student, in the first year specifically, are, in the view of the staff, to transition to university studies, to learn valuable work and study skills and to become part of a valued community. The first of those capabilities ( 3 on the list) was recognized by the participants and discussed in some detail in their ADPRP interviews. The students appreciated and benefitted from the decreased load, both academically and otherwise, and positive assessment data provide quantitative verification, justifying their confidence in the transition process. The study skills gained by the students ( 4 on the list) are emphasized more by the Programme documentation than by the students themselves. This is not to say that the students have not gained those skills - they may well have - but they were not foregrounded in the students' perception of the capabilities gained by being a member of ASPECT. The fact that students did not mention the communication course is cause for concern, however, and this could be addressed by increasing the credit value of the course, making the need for the skills more explicit, or integrating the communication skills into the other courses. The valuable state of being a 
This article is a post-review, pre-publication version of a book chapter. For citation purposes, please see the original: Craig, T.S. (2017). Enabling capabilities in an Engineering extended curriculum programme. In R. Kapp \& B. Bangeni (Eds.) Negotiating Learning and Identity in Higher Education. Bloomsbury Press.

member of the ASPECT community ( 2 on the capabilities list) is mentioned in the Programme documentation, but not nearly to the extent that the students mentioned it.

The Programme also tries to develop the capability to transition to second year and further, beyond the immediate reach of the ASPECT staff members, but with the necessary skills for coping. Some students, such as Senzo and Simphiwe gained those skills. Others did not seem to, such as Fatima and Siphilisiwe. In addition, structural challenges beyond the control of the students and the ASPECT staff can prevent the smooth conversion of capabilities into functionings.

\section{Continuing the journey: Transitioning into second year and beyond}

In their second year at the university, ASPECT students have a mixed curriculum of first- and second-year subjects. They are required to take more courses and they are no longer provided with additional academic support. They are now in larger classes, with fewer contact hours per subject than before. The work is often more cognitively demanding than in first year. The close-knit community of first year begins to break apart as students take courses specific to their engineering disciplines. All of these changes make for a substantial adjustment which is frequently troublesome and hinders the conversion of the capability into the achieved functioning of transitioning. Constraints such as 'classroom pedagogy and management' or a lack of 'cultures of concern with learners' difference' might render the implementing of the capability as a functioning very difficult (Walker and Unterhalter 2007:10).

The year of immersion in the ASPECT system, with all its support structures, is intended to develop the capability (the potential) to transition to second year successfully, yet the functioning (actual achievement) of coping with second-year demands was not experienced by all the students in the study. The capabilities have possibly been enabled but cannot be put into practice (Walker 2003). The participants' views, as recorded in their interviews, and the Programme's declarations of intent are in accord about this capability being crucial to success:

Although ASPECT is only a first-year programme the intention is to prepare students for further years of study and to graduate (ASPECT Review 2009: $16)$

The aim of ASPECT is to improve on the number of black and coloured student graduates as well as the graduation rate of these students in the EBE faculty. This is achieved by providing the students that enter the programme with the best possible preparation to succeed in the following years in their engineering studies, through excellent teaching, building a supportive learning community, recognition of the level of the preparedness and being attentive to students. (ASPECT Review 2009: 4)

It is frequently the case that ASPECT students struggle to cope with the changes as they shift from the supported first year to the less supported second year (see also Pym and Kapp 
This article is a post-review, pre-publication version of a book chapter. For citation purposes, please see the original: Craig, T.S. (2017). Enabling capabilities in an Engineering extended curriculum programme. In R. Kapp \& B. Bangeni (Eds.) Negotiating Learning and Identity in Higher Education. Bloomsbury Press.

2013). The capability to handle the workload and larger classes of mainstream studies failed to transform into successful functioning and the participants' experience did not live up to the optimism of the Programme expectations:

It [ASPECT] helped, but then when we got to second year... You know how you hold a baby when they learn to walk, right, and then once they start walking just let them walk on their own. So I felt like, in second year, ok, so now, baby, you have wings, now fly, but some of us couldn't fly... (Tsego, interview 3);

Ifeel like there is so much support during first year and then after that it is like - ja, do your thing, I don't know like sometimes it feels like you somehow still need the support like throughout, so.... (Rethabile, interview 4)

A few of the students reported that the transition to second year was aided by having observed first-year mainstream loads, but that the tough transition then just shifted to third year.
Although we were ASPECT, we still interacted with other students who were in mainstream, so we could see how pressurised they were and we knew that it was coming, so it was kind of, either you prepare for it or you just have to see how you move through it when your pressure comes, you are prepared I think, in second year (Tsego, interview 5);
Well, I guess the lowlight was discovering that ASPECT was kind of just a start-off, it was just a little push in the right direction and then after like the first two years, now we must cut the apron.... (Tsego, interview 5)
So first year courses were mostly a recap or a spin-off of matric work, so maths and science and etc., but last year [third year] was all new work and so they keep the same pace but it is all new so it was difficult to get a handle on it. (Leonard, interview 4)

The data point to the possibility of there being too much support in first year. Couple this 'over support' with a student perception (whether justified or not) of a lack of concern on the part of the staff towards the abrupt transition and we inevitably have students who stumble and fall. Pym and Kapp (2013:273) recognize the danger of too much support in the first year at university, arguing that it 'encourages passivity and dependence, thus stripping students of the agency which enabled them to attain access to tertiary studies despite their home and school circumstances'. Yet, decreasing support in first year is not an inevitable response to the difficulty of transitioning from a support-heavy environment to a support-light one. The dilemma is that it is the self-same support which enables students to succeed in their firstyear studies. 
This article is a post-review, pre-publication version of a book chapter. For citation purposes, please see the original: Craig, T.S. (2017). Enabling capabilities in an Engineering extended curriculum programme. In R. Kapp \& B. Bangeni (Eds.) Negotiating Learning and Identity in Higher Education. Bloomsbury Press.

Tsego's motif of 'ASPECT as crèche' is a good example of a theme repeated vertically through the data:

'You know how you hold a baby when they learn to walk ... ok, so now, baby, you have wings, now fly' (interview 3);

'Here is a life vest - swim' (interview 4) and

'Now we must cut the apron' (interview 5).

Such instances provide us with a sense of narrative coherence in Tsego's 'life history' (Thomson 2009: 13) while simultaneously underlining the perception of too much support followed by a sudden disappearance of support.

The struggles of the students to cope with the pressures of advanced years within the degree are known to the ASPECT staff and were acknowledged in the review:

A one year foundational experience has not proved to be adequate to erase the effects of years of inadequate preparation. Many have been excluded in the first few years of being with the mainstream. Some criticism levelled at the ASPECT model has attempted to suggest that the students fail in second year because there is too much support in first year and then it is suddenly withdrawn. 'Spoon-feeding' is often mentioned. (ASPECT Review 2009:

In addition to trying to instil work and study skills which will allow students to transition to the increased workload and cognitive demands of second-year courses (capability 5), the Programme aims to provide help in the practicalities of the transition by providing ongoing curriculum advice and a structured navigation plan. A student entering the faculty via the ASPECT programme has their five-year plan mapped out for them. Approximately a third of all students who register for a mainstream engineering degree complete in the minimum time of four years (Scott, Yeld and Hendry 2007). Most students fail one or more courses and have to repeat the courses they fail. If a course which is a prerequisite for subsequent courses has to be repeated, the degree is extended. Entering the university through ASPECT sets the student up to complete the degree in five years with an explicitly designed curriculum structure to make that possible. The students in the study recognized the distinction between their five-year structured programme, with continued curriculum advice throughout their stay at UCT, and the five-year experience of a mainstream student who has failed something and struggles to reconcile their timetable and make up lost credits. This is reflected in the comments below:

Honestly speaking, I feel like it is of an advantage because like most of the people, ..., like they have either maybe repeated a course or something, like eventually they also have to do it for five year, so at least I have something structured (Rethabile, interview 2);

I think if I didn't choose ASPECT I would still be doing 5 years in ChemEng again... because maths first year... sho hey... ... So, ja, maths was giving me problems. So I went to ASPECT then I passed it. I don't think that if I 
had stayed in mainstream I could have... I could have passed it. ... Now they're like me, who am in ASPECT... they'll finish with me in 5 years. So I don't feel bad. (Nwabisa, interview 3)

The struggles of students to graduate with an engineering degree is an area of great concern, both locally and nationally. It is crucial that students who enter universities through special entry programmes are given the skills to progress further than just the first year of studies. Widening participation in higher education through access is a wasted benefit if transitioning through the more advanced years of study is not similarly supported (Badat 2013).

\section{Journey's end: Graduating}

Of the fifteen students taking part in the study, five graduated in 2013 in minimum time (five years) and three graduated in 2014 and one in 2015. At the time of writing, one student continues in good academic standing and five left the university during the period of study. The graduation rate of the students taking part in the study is currently 60 per cent and could rise as high as 66 per cent. These figures are rather higher than typical, with an approximate 35 per cent eventual graduation rate expected from the extended programme's historical data.

Recall that most of the participants in the study would not have been accepted into the University at all (and hence have a graduation rate of 0 per cent), or were struggling so much in their first six weeks of first-year mainstream studies that their chance of passing even first year was small, let alone graduating. For at least some of these students the capability to graduate has been converted into an actual graduation. Structuring the degree to extend over five years, with the first two years of mainstream study effectively spread over three years, is the primary characteristic of the Programme and is understood to be the reason why students can achieve the 'valuable act' of being able to graduate:

'The ASPECT programme's model of intervention can be classified as a model of "extended" curriculum. The curriculum is planned so that the four-year engineering degree should ideally take five years to complete' (ASPECT Review 2009: 6).

In certain cases, students in ASPECT who consider themselves capable of 'fast tracking' their degree and completing in four years can register for more courses than recommended. The ASPECT curriculum advisors generally advise against such a choice. Leonard is one student who chose to take on extra courses in an ultimately unsuccessful bid at graduating early. In his first year, he expressed ambivalence about being part of ASPECT:

... in ASPECT, the teaching is better, one on one, like if you have any problems you go, they make sure you understand it but on the other hand I want to finish in four years, so ASPECT was a good thing for me, but now that I've, I'm in the motion of doing well and working I'm focusing on finishing in four years, so like I'm doing Engineering Statics now, which is not an ASPECT [first-year] course, so I wanted to take more courses in the 
This article is a post-review, pre-publication version of a book chapter. For citation purposes, please see the original: Craig, T.S. (2017). Enabling capabilities in an Engineering extended curriculum programme. In R. Kapp \& B. Bangeni (Eds.) Negotiating Learning and Identity in Higher Education. Bloomsbury Press.

beginning and they said if I do well in the semester, then I'd be able to, so now I'm going to fast track my degree. (Leonard, interview 1)

This quotation reflects the fact that while the Programme is designed to extend the degree and is expected to increase the chances of functionings such as transitioning and graduation, students view the extended time as a constraining feature, hampering their chances of an earlier graduation.

\section{Conclusion}

It is a feature of good governance to provide citizens with opportunities for good quality education. Under most circumstances, but particularly under circumstances of great social inequality or class stratification (Walker 2003), it is a matter of social justice that the available educational opportunities be designed to widen participation to all sectors of the population. Tikly and Barrett (2011: 11) argue that there are three dimensions of a good quality education from a social justice perspective:

1. The inclusion dimension, concerned with access and opportunities;

2. The relevance dimension, concerned with meaningful learning outcomes (see also Wood and Deprez 2012);

3. The democratic dimension, concerned with 'issues of participation and voice' and drawing 'attention to the fundamentally political nature of the debate about education quality'.

In the South African context, and in other countries with similar socio-economic inequalities, it is not enough that universities with good schools of engineering, medicine and other fields of study, exist. The inclusion dimension (and indeed the democratic dimension) of a good quality education demands that at least some of those universities, if not all, explicitly create opportunities for previously-marginalized sections of the population to gain access to fields of study considered relevant and valuable, such as engineering.

One way in which universities across South Africa have chosen to address the inclusion dimension, is to create access routes into university for students who are judged to have the capacity to succeed at university, yet cannot achieve so-called mainstream access, for a range of reasons related to socio-economic structures and the lingering effects of South Africa's apartheid history. Over the last twenty years, there has been some significant success (Badat 2013) with respect to social justice, access and success in higher education. ASPECT forms part of UCT's process of addressing this issue through admissions and through access to resources. As such, the Programme is located within a 'pedagogy of consequence' (Unterhalter 2010) where inequality is recognized and addressed in a context of differentiated fields of disciplinary knowledge. While programmes like ASPECT partially meet social justice aims, high drop-out rates and low graduation rates persist among black students. The Education White Paper of 1997 expressed a concern that remains valid today, that 'ensuring equity of access must be complemented by a concern for equity of outcomes' (Department of Education 1997:16, 2:29). 
The capability approach, with its focus on converting resources into capabilities and thereafter (ideally) into functionings offers a means of assessing the effectiveness of pedagogies and the structures within which they are located for fostering well-being and the ability to choose a life of value. '[W]e need to know what we are trying to make and to be able to judge whether we have made it well' (Walker 2003:169). Since ASPECT forms one small part of the local and national agenda of transformation and social justice in education, it is important that we know 'what we are trying to make' and 'whether we have made it well'. The approach taken in this chapter towards judging the efficacy of the ASPECT programme was to compare and contrast the envisioned capability development as expressed in the Programme documentation with the experienced capability development as expressed in student interviews across five years of engineering studies. A positive conclusion reached through this method is that the access role of the Programme is being successfully recognized and realized as are the first-year pedagogic processes related to transitioning from school to university study.

While access to higher education is a necessary part of good quality tertiary education, it is not sufficient (Walker 2003; Badat 2013). A major area of concern relates to the identity of ASPECT as primarily a first-year programme and the pronounced differential between the amount of support available in first-year ASPECT on the one hand, and second-year studies and beyond on the other. Many students claim that the support provided in that first crucial year is instrumental in guaranteeing their success, yet 'nowhere is education an uncomplicated "good"' (Walker 2003:169) and that same support is blamed for making the proceeding years more challenging than they might otherwise have been. Addressing this apparent dilemma, of support being simultaneously crippling and enabling, can be tackled by shifting focus and dealing with the differential instead. One such treatment is to extend ASPECT support beyond first year into, for instance, second-year Mathematics (Craig and Campbell 2013) and possibly other courses. This approach holds the amount of support in first year steady, while allowing the support to taper off, rather than disappear abruptly, in second year. A parallel approach is to integrate the reading, writing and presenting skills of the communication course into engineering courses, a process underway at the time of writing. The integration of communication skills into disciplinary studies increases the perceived relevance of those skills and avoids students seeing them as an 'add on'.

Working through the data for this longitudinal project, it has become clear that the community feature of ASPECT is very important to the students, more important than the Programme officially recognizes. The emphasis on community throughout the 'snapshot' interviews (Thomson 2009: 14) provided narrative coherence both horizontally and vertically within the data set. The research on 'learning communities' indicates that participation in a robust learning community has positive effects not just academically, but emotionally and socially. A 'learning community' is defined as a cohort of students who take two or more courses together, and who are generally involved in out-of-class activities together (Pike, Kuh 
and McCormick 2011; Goldman 2012). Learning communities can have a residential component and frequently include peer mentoring. Research has shown that participation in a learning community is linked to higher levels of student achievement, learning and success (Pike, Kuh and McCormick 2011; Goldman 2012; Hatch 2013). The link between community participation and positive academic effects is indirect, with participation resulting in student engagement which in turn results in improved 'grades in college, desired learning outcomes, satisfaction with college, and persistence and graduation' (Pike, Kuh and McCormick 2011: 301). This evidence supports the argument that the development of an appropriate identity (in this case as a novice engineer) leads to engagement and hence positive academic results (Cobb and Hodge 2005; Cobb, Gresalfi and Hodge 2009; Craig 2013). The creation of a tight-knit learning community in the first-year cohort is due in part to the actions and input of the staff but far more to the agency of the students themselves, who recognize the value of the academic and psycho-social support they receive from their peers.

A promising avenue to explore is whether extending the ASPECT activities to include out-ofclass (possibly non-academic) activities would have an indirect positive effect on issues such as the multiple transitions the students experience or on study habits. Pike, Kuh and McCormick (2011) cite Szelényi et al. (2007), who found evidence to suggest that the positive relationship between learning community participation and a successful transition to college was stronger for low socio-economic status students, as ASPECT students generally are. The work done on 'wellness' at the University of Stellenbosch near Cape Town has interesting parallels, with wellness defined by 'six domains of human existence, namely, the intellectual, social, emotional, physical, spiritual, and occupational domain' (Botha and Cilliers 2012: 244).

Agreement between student voice and Programme documentation suggests that 'to be a university student' and to 'transition to university studies' are fully developed functionings. The data do not show clearly whether the participants 'learnt work habits and study skills'. 'To transition into second year and beyond' is the capability least enabled and least likely to achieve status of a functioning, with obvious implications for 'to graduate in five years'. I argue that the weaknesses in the system thrown into relief by the analysis discussed in this chapter can be addressed by a two-pronged approach of direct academic intervention (extension of support slightly beyond first year and integrating communication skills into disciplinary studies) as well as indirectly by explicitly fostering a learning community in ways which, ideally, will have positive effects, academically, socially and emotionally.

The longitudinal project has provided a unique opportunity to trace students' journeys through their degree and to foreground their voices: the satisfaction in being granted access to university studies, the struggles to adapt to first-year studies, the second-year transition and beyond, the emotional ups and downs, the good times and the bad. The capability approach has provided a language with which to discuss the aims of the Programme and to recognize the successes and the shortfalls. The ASPECT extended curriculum programme plays its own 
This article is a post-review, pre-publication version of a book chapter. For citation purposes, please see the original: Craig, T.S. (2017). Enabling capabilities in an Engineering extended curriculum programme. In R. Kapp \& B. Bangeni (Eds.) Negotiating Learning and Identity in Higher Education. Bloomsbury Press.

small part in providing social justice in South Africa and, with research such as discussed here, will improve its offerings to afford students the freedom to choose a life of value.

\section{References}

Academic Support Programme for Engineering in Cape Town (2008), 'ASPECT Brochure', unpublished internal UCT brochure, available from author.

Academic Support Programme for Engineering in Cape Town (2009), 'ASPECT Review', unpublished internal UCT review, available from author.

Badat, S. (2013), 'The Limits of Access, Success and Social Justice in Post-1994 South African Higher Education: Building the Learning and Teaching Capabilities of Universities', Keynote address, Second Biennial Conference of the South African Society for Engineering Education, 10-12 June, Cape Town, South Africa.

Botha, L. and Cilliers, C. (2012), “ "Adolescent” South Africa (18 Years since

Democratization): Challenges for Universities to Optimize Wellness as a Prerequisite for Cognitive Development and Learning in a Diverse Society', Journal of Cognitive Education and Psychology, 11(3): 241-255.

Case, J.M. (2013), Researching Student Learning in Higher Education: A Social Realist Approach, Oxford: Routledge

Christie, P. (2010), 'The Complexity of Human Rights in Global Times: The Case of the Right to Education in South Africa', International Journal of Educational Development, 30: 3-11.

Cobb, P. and Hodge, L.L. (2005), 'An Interpretive Scheme for Analysing Identities that Students Develop in Mathematics Classrooms', http://www.udel.edu/educ/whitson/897s05/files/Cobb_ID.pdf, accessed 29 July 2016.

Cobb, P., Gresalfi, M. and Hodge, L.L. (2009), 'An Interpretive Scheme for Analysing the Identities that Students Develop in Mathematics Classrooms', Journal for Research in Mathematics Education, 40(1): 40-68.

Craig, T.S. (2013), 'Conceptions of Mathematics and Student Identity: Implications for Engineering Education', International Journal of Mathematics Education in Science and Technology, 44(7): 1020-1029.

Craig, T.S. and Campbell, A. (2013), 'Vector Calculus for Engineers - The Academic Development Model', Community for Undergraduate Learning in the Mathematical Sciences (CULMS) Newsletter, 7: 21-25.

Department of Education (1997), 'Education White Paper 3: A Programme for the Transformation of Higher Education', Government Gazette No. 18207.

Goldman, C.A. (2012), 'A Cohort-Based Learning Community Enhances Academic Success and Satisfaction with University Experience for First-Year Students', The Canadian Journal for the Scholarship of Teaching and Learning, 3(2) Article 3: 1-19.

Hatch, D.K. (2013), 'Student Engagement and the Design of High-Impact Practices at Community Colleges', unpublished Ph.D. thesis, University of Texas, http://repositories.lib.utexas.edu/handle/2152/21775, accessed 29 July 2016. 
Jawitz, J. (1994), 'Developments in the Academic Support Programme for Engineering in Cape Town (ASPECT)', in Adey et al. (eds) State of the Art in Higher Education Volume 1, Proceedings of the 9th Biannual SAARDHE Conference, Cape Town.

Jawitz, J. and Scott, L. (1997), 'Who Does Not Succeed in Engineering at the University of Cape Town? What Can One Tell from the Retention Rate?', presented at the 1997 Frontiers in Education Conference.

Kapp, R., Badenhorst, E., Bangeni, B., Craig, T.S., Janse van Rensburg, V., le Roux, K., Prince, R., Pym, J. and van Pletzen, E. (2014), 'Successful Students' Negotiation of Working-Class Schooling in Post-Apartheid South Africa', Perspectives in Education 32(3): 50-61.

Kloot, B., Case, J.M. and Marshall, D. (2008), 'A Critical Review of the Educational Philosophies Underpinning Science and Engineering Foundation Programmes', South African Journal of Higher Education, 22(4): 799-816.

Meyer, J.H.F. and Sass, A.R. (1992), 'Engineering Students from Educationally Disadvantaged Backgrounds: Assumptions, Research Conclusions, and Curriculum Responses', International Journal of Engineering Education, 8(5): 328-335.

Nussbaum, M. (2006), 'Education and Democratic Citizenship: Capabilities and Quality Education', Journal of Human Development, 7(3): 385-395.

Pearce, H., Campbell, A., Craig, T.S., le Roux, P., Nathoo, K. and Vicatos, E. (2015), 'The Articulation between the Extended (5-year) and Mainstream (4-year) Programmes in Engineering at the University of Cape Town: Reflections and Possibilities', South African Journal of Higher Education, 29(1): 151-164.

Pike, G.R., Kuh, G.D. and McCormick, A.C. (2011), 'An Investigation of the Contingent Relationships between Learning Community Participation and Student Engagement', Research in Higher Education, 52: 300-322.

Pym, J. and Kapp, R. (2013), 'Harnessing Agency: Towards a Learning Model for Undergraduate Students', Studies in Higher Education, 28(2): 272-284.

Robeyns, I. (2003), 'Sen's Capability Approach and Gender Inequality: Selecting Relevant Capabilities', Feminist Economics, 9(2-3): 61-92.

Sass, A. (1988), 'Academic Support in Engineering at the University of Cape Town', South African Journal of Higher Education, 2(1), 25-28.

Scott, I., Yeld, N., and Hendry, J. (eds) (2007), 'A Case for Improving Teaching and Learning in South African Higher Education', Higher Education Monitor, No.6,Pretoria: Research Paper Prepared for the Council on Higher Education,

Sen, A. (1993), 'Capability and Well-Being', in M. Nussbaum and A. Sen (eds), The Quality of Life: Studies in Developmental Economics, Oxford : Oxford University Press.

Thomson, R. (2009), Unfolding Lives: Youth, Gender and Change, Portland: The Policy Press.

Tikly, L. and Barrett, A.M. (2011), 'Social Justice, Capabilities and the Quality of Education in Low Income Countries', International Journal of Educational Development, 31: 314. 
This article is a post-review, pre-publication version of a book chapter. For citation purposes, please see the original: Craig, T.S. (2017). Enabling capabilities in an Engineering extended curriculum programme. In R. Kapp \& B. Bangeni (Eds.) Negotiating Learning and Identity in Higher Education. Bloomsbury Press.

Unterhalter, E. (2010), 'Considering Equality, Equity and Higher Education Pedagogies in the Context of Globalization', in E. Unterhalter and V. Carpentier (eds), Universities into the 21st Century: Global Inequalities and Higher Education. Whose Interests Are We Serving? Basingstoke, Hampshire UK: Palgrave Macmillan.

Walker, M. (2003), 'Framing Social Justice in Education: What does the "Capabilities" Approach Offer?', British Journal of Educational Studies, 51(2): 168-187.

Walker, M. (2005), ‘Amartya Sen's Capability Approach and Education', Educational Action Research, 13(1): 103-110.

Walker, M. (2006), 'Towards a Capability-Based Theory of Justice for Education PolicyMaking', Journal of Educational Policy, 21(2): 163-185.

Walker, M. and Unterhalter, E. (2007), 'The Capability Approach: Its Potential for Work in Education', in M. Walker and E. Unterhalter (eds), Amartya Sen's Capability Approach and Social Justice in Education, Palgrave Macmillan: New York.

Wood, D. and Deprez, L.Z. (2012), 'Teaching for Human Well-Being: Curricular Implications for the Capability Approach', Journal of Human Development and Capabilities: A Multidisciplinary Journal for People-Centred Development, 13(3): 471-493. 